\title{
Diabetes and carotid artery disease: a narrative review
}

\author{
Niki Katsiki ${ }^{1}$, Dimitri P. Mikhailidis ${ }^{2,3}$ \\ ${ }^{1}$ Diabetes Center, Division of Endocrinology and Metabolism, First Department of Internal Medicine, AHEPA University Hospital, Medical School \\ Aristotle University of Thessaloniki, Thessaloniki, Greece; ${ }^{2}$ Department of Clinical Biochemistry, Royal Free Hospital Campus, University College \\ London Medical School, University College London (UCL), London, UK; ${ }^{3}$ Mohammed Bin Rashid University of Medicine and Health Sciences, \\ Dubai, United Arab Emirates \\ Contributions: (I) Conception and design: All authors; (II) Administrative support: None; (III) Provision of study materials or patients: None; (IV) \\ Collection and assembly of data: All authors; (V) Data analysis and interpretation: All authors; (VI) Manuscript writing: All authors; (VII) Final \\ approval of manuscript: All authors. \\ Correspondence to: Niki Katsiki, MSc, PhD, MD, FRSPH. Diabetes Center, Division of Endocrinology and Metabolism, First Department of Internal \\ Medicine, AHEPA University Hospital, Thessaloniki, Greece. Email: nikikatsiki@hotmail.com.
}

\begin{abstract}
Diabetes mellitus (DM) has been linked to an increased prevalence and severity of carotid artery disease, as well as polyvascular disease. Carotid disease is also associated with obesity and abnormal periorgan and intra-organ fat (APIFat) deposition (i.e., excess fat accumulation in several organs such as the liver, heart and vessels). In turn, DM is associated with APIFat. The coexistence of these comorbidities confers a greater risk of vascular events. Clinicians should also consider that carotid bruits may predict cardiovascular risk. DM has been related to a greater risk of adverse outcomes after carotid endarterectomy or stenting. Whether modifying risk factors (e.g., glycaemia and dyslipidaemia) in DM patients can improve the outcomes of these procedures needs to be established. Furthermore, DM is a risk factor for contrastinduced acute kidney injury (CI-AKI). The latter should be recorded in DM patients undergoing carotid stenting since it can influence both short- and long-term outcomes. From a pathophysiological perspective, functional changes in the carotid artery may precede morphological ones. Furthermore, carotid plaque characteristics are increasingly being studied in terms of vascular risk stratification and monitoring shortterm changes attributed to treatment. The present narrative review discusses the recent (2019) literature on the associations between DM and carotid artery disease. Physicians and vascular surgeons looking after patients with carotid disease and DM should consider these links that may influence outcomes. Further research in this field is also needed to optimise the treatment of such patients.
\end{abstract}

Keywords: Diabetes; carotid artery disease; stroke; vascular risk; epicardial fat; non-alcoholic fatty liver; carotid bruits

Submitted Nov 11, 2019. Accepted for publication Dec 23, 2019.

doi: $10.21037 /$ atm.2019.12.153

View this article at: http://dx.doi.org/10.21037/atm.2019.12.153

\section{Introduction}

There has been a considerable increase in the literature related to diabetes mellitus (DM) and carotid artery disease (Table 1). This trend reflects current interest in this topic. In this narrative review, we focused on the recent (2019; last accessed 3 November 2019) literature (in PubMed) with the aim to highlight some key issues regarding the links between DM and carotid disease. This association has considerable clinical relevance for both physicians and surgeons.
Treatment issues will not be addressed since they are well covered by recent guidelines and some of the other reviews in this special issue $(1,2)$.

\section{Does DM increase the risk of developing carotid disease?}

It is well established that DM is associated with an increased risk of vascular events (1). Nevertheless, more recent studies 


\begin{tabular}{lc}
$\begin{array}{l}\text { Table } 1 \text { Number of entries on PubMed 1969-2019 under “carotid } \\
\text { diabetes" (last accessed } 3 \text { Nov 2019; https://www.ncbi.nlm.nih.gov/ } \\
\text { pubmed/?term=carotid+diabetes) }\end{array}$ \\
\hline Year & Number of entries \\
\hline 2019 & 416 \\
2009 & 302 \\
1999 & 125 \\
1989 & 38 \\
1979 & 7 \\
1969 & 4 \\
\hline
\end{tabular}

are also of interest.

\section{DM, stroke and vascular risk}

DM increases the risk of ischaemic stroke in the general population (3) and can also aggravate the severity of extracranial atherosclerotic disease (4). Moreover, as far back as 2010, the European Society of Vascular Surgery (ESVS) "carotid" guidelines (5) emphasised the increased vascular event risk associated with DM. Updated recommendations are provided in the more recent (2018) and comprehensive ESVS guidelines (2).

\section{Glycaemic control and carotid disease}

In a cross-sectional study $[\mathrm{n}=2,215$ patients with type 2 DM (T2DM)], glycaemic control [expressed as time in range (TIR)] was associated with carotid intima-media thickness (cIMT) (6). For the normal cIMT group $(\mathrm{n}=1,944)$ age was $59.5 \pm 11.8$ years and $53.2 \%$ were males; for the abnormal cIMT group $(\mathrm{n}=271)$ the corresponding values were: $67.0 \pm 9.6$ years and $63.5 \%$ were males. TIR was defined as glucose levels in the range of $3.9-10.0 \mathrm{mmol} / \mathrm{L}$ $(70-180 \mathrm{mg} / \mathrm{dL}$ ) (assessed by continuous subcutaneous glucose monitoring for 3 days) (6). Compared with patients with a normal cIMT, those with a mean cIMT $\geq 1.0 \mathrm{~mm}$ had significantly lower TIR $(\mathrm{P}<0.001)$. In particular, each $10 \%$ increase in TIR was related to a $6.4 \%$ lower risk of abnormal cIMT (6).

Similar findings were observed in another study involving 1,065 patients with neurological asymptomatic carotid atherosclerosis (median follow up: 11.8 years) (7). DM was diagnosed in 335 (31.5\%) of the participants; most had T2DM (95.3\%). In this study, the adjusted hazard ratio
(HR) for every $1 \%$ increase in glycated haemoglobin $\left(\mathrm{HbA}_{1 \mathrm{c}}\right)$ levels was $1.31(\mathrm{P}<0.01)$ for cardiovascular $(\mathrm{CV})$ mortality and $1.21(\mathrm{P}<0.01)$ for all-cause mortality, respectively $(7)$.

\section{Severity of carotid stenosis in patients with DM and risk of adverse outcomes}

The severity of carotid stenosis in patients with DM may confer an increased risk of adverse outcome. In the study by Hoke et al. (7), described above, there were 4 groups of patients: no DM and $<50 \%$ carotid stenosis, DM and $<50 \%$ carotid stenosis, no DM and $\geq 50 \%$ carotid stenosis and DM and $\geq 50 \%$ carotid stenosis. Only $21 \%$ of the diabetic patients with asymptomatic carotid narrowing $\geq 50 \%$ survived. In contrast, $40 \%$ of those without DM and asymptomatic carotid narrowing $\geq 50 \%$ survived. Also, $62 \%$ of the patients without DM and with asymptomatic carotid artery narrowing $<50 \%$ were still alive after a median follow-up of 11.8 years $(\mathrm{P}<0.01$ for trend). This high risk associated with $\mathrm{DM}$ remained significant after adjusting for several established $\mathrm{CV}$ risk factors in a multivariable regression analysis (7). The increased mortality in those with DM was attributed to higher all-cause and CV mortality.

\section{Changes in cIMT and carotid function indices start early in life}

The harmful effects of DM on the carotid arteries seem to start early in life since an increased cIMT has been reported among children (mean age $=12.15 \pm 2.59$ years) with type 1 DM (T1DM) (8). This finding may reflect the influence of several predictors of vascular risk factors that were identified in these patients. Changes in arterial function and aortic IMT were also observed in this population (8). These findings are supported by a meta-analysis involving 20 cIMT studies and 4 carotid-femoral pulse wave velocity studies (9). The trend may be initiated even earlier since a link between gestational DM, maternal obesity, child lean body mass and weight gain in childhood and cIMT has been reported (10).

\section{Renal events and cIMT}

As expected, there is evidence supporting that resistant hypertension increases the risk of developing complications in those with T2DM (11). The same study (the Rio de Janeiro type 2 diabetes cohort study) also showed that 
cIMT and the presence of carotid plaques predicted CV events and renal outcomes, but not mortality or other microvascular complications (12).

\section{Multisite arterial disease and cIMT}

Multisite atherosclerosis was assessed in CV disease (CVD)-free participants ( $\mathrm{n}=1,675 ; 51 \%$ males, mean age: 64 years) from the Multi-Ethnic Study of Atherosclerosis (MESA); 33.4\% had metabolic syndrome (MetS) and 15.9\% had DM (13). The involvement of several arterial beds was recorded: coronary arteries (as coronary calcium), abdominal aorta (as aortic calcium), carotids (as cIMT $\geq 1 \mathrm{~mm}$ ) and peripheral artery disease (PAD) [as ankle brachial index (ABI), <1 or $\geq 1.4]$. The number of atherosclerotic sites identified was significantly $(\mathrm{P}<0.0001)$ higher in the participants with $\mathrm{DM}$ (mean $\pm \mathrm{SD}=1.67 \pm 1.15)$ and MetS $(1.49 \pm 1.12) v s$. neither MetS nor DM (1.09 \pm 1.09$)$ (13). CVD rates/1,000 person-years ranged from $3.5,8.2$, and 10.0 in those with 0 arterial sites positive to 35.1, 79.6 and 103.4 in those with four arterial sites positive among neither DM nor MetS, MetS and DM groups, respectively (13).

\section{PAD and cIMT}

PAD has been associated with increased cIMT. In a study involving patients with diabetic foot, more patients with PAD had cIMT $\geq 0.71 \mathrm{~mm}(79.65 \%$ vs. $38.89 \%$; $\mathrm{P}<0.001)$ and internal carotid arteries (ICA) plaques $(66.37 \%$ vs. $11.11 \% ; \mathrm{P}<0.001)$ than those without PAD (14). This study is of interest since it includes data on carotid plaques. According to recent guidelines, attention has drifted away from the cIMT to carotid plaque presence and area (1). The reason for this change is that plaque presence and area are likely to reflect more rapid changes in the carotid arteries. A recent comprehensive review as well as an editorial discussing the value of measuring carotid plaque area and its other characteristics are available $(15,16)$.

The importance of carotid plaque was demonstrated in a study where CV events in patients with T2DM without manifest CVD were associated with greater median carotid plaque area [30.4 (16.1-92.2) vs. $19.5(9.5-40.5) \mathrm{mm}^{2}$, $\mathrm{P}=0.01]$ (17). Similarly, in another study, the only variable predicting $\mathrm{CV}$ events among patients with $\mathrm{DM}$ and chronic kidney disease was the number of carotid and femoral arterial territories with plaque at baseline [HR 1.782, 95\% confidence interval (CI): 1.393-2.278] (18). Furthermore, in a cross-sectional analysis involving 3,815 Chinese community-dwelling adults, T2DM, hypertension and decreased estimated glomerular filtration rate (eGFR) were independently related to the presence, number and total area of carotid plaque (19).

$\mathrm{PAD}$ is often undiagnosed in asymptomatic patients with T1DM and may coexist with carotid artery disease (20). It is relevant to consider that medial artery calcification can be found in up to $47 \%$ of patients with T1DM (20). Therefore, the ABI may underestimate the prevalence of PAD (20). This information would be clinically relevant since it may influence patient management. Furthermore, PAD may be a part of a polyvascular disease in some patients with all forms of DM.

A link between asymptomatic carotid artery stenosis (ACAS) and PAD has also been reported; this association may be influenced by age and hypercholesterolaemia (21).

\section{Carotid function and cIMT}

It is also relevant to consider that functional changes in the carotid artery may precede morphological ones (22). Indeed, an increase in cIMT in patients with DM can be accompanied by abnormalities in function (e.g., carotid wave speed, carotid artery distensibility and carotid-femoral pulse wave velocity) $(23,24)$.

\section{Carotid plaque characteristics and DM}

Patients with T1DM have different carotid plaque types compared with individuals without T1DM (25). This includes an increased frequency of echogenic and extensively calcified plaques. This finding needs to be confirmed but it may well represent a trend for calcification in these patients. Whether, this difference represents an increased risk of vascular events remains unclear but worthy of further investigation (26).

\section{Comments}

There is evidence of a link between "glycaemia" and carotid pathology (as represented by cIMT and some function indices) and the risk of vascular events (including kidney function). Although this relationship appears to be timerelated, it starts "early" in children with T1DM. Another message is "always look for polyvascular disease" when you see carotid disease. Polyvascular disease is associated with a greater risk of vascular events.

There is considerable discussion regarding plaque area 
vs. cIMT in terms of predicting vascular risk and also for monitoring short-term changes attributed to treatment.

Finally, we always need to consider the overall high vascular risk associated with DM $(1,26)$.

\section{DM and carotid endarterectomy (CEA) and carotid artery stenting (CAS)}

In the SAPPHIRE (Stenting and Angioplasty with Protection in Patients at High Risk for Endarterectomy) trial (748 operations; follow-up: 13 years), previous myocardial infarction (MI) (HR 2.045, 95\% CI: 1.108-3.777, $\mathrm{P}=0.022$ ), DM (HR 2.111, 95\% CI: 1.183-3.767, $\mathrm{P}=0.011$ ) and symptomatic patients [previous stroke or transient ischaemic attack (TIA); HR 2.045, 95\% CI: 1.018-4.109, $\mathrm{P}=0.044]$ were independently associated with major adverse $\mathrm{CV}$ and cerebrovascular events (MACCE) (27).

A recent analysis of the effect of best medical therapy (BMT; 162 patients) vs. carotid surgical revascularization (CRevasc; 247 patients) + BMT in patients with ACAS (>70\% stenosis) was carried out (mean follow-up: $60.7 \pm 37.5$ months) (28). Ipsilateral stroke and any stroke at 1 and 5 years were comparable between the 2 groups. However, patients with a history of DM and remote stroke treated with BMT only were at a high risk for future stroke (7.2\%/year). CRevasc + BMT patients with DM and contralateral $>50 \%$ carotid stenosis who were smokers had the highest risk for stroke (28).

In a meta-analysis of 18 studies (17,106 patients), DM (HR 1.68; 95\% CI: 1.00-2.83; $\mathrm{I}^{2}=76.7 \%$ ), among other factors (e.g., dyslipidaemia, chronic kidney disease, female gender, smoking, hypertension, and baseline stenosis $>70 \%$ ) were associated with a significant increased risk of restenosis after CRevasc (29).

Another study included 16,739 CEA patients; $58 \%$ had ACAS (30); there were patients with no DM (69\%), noninsulin-dependent DM (NIDDM) (20\%) and insulindependent DM (IDDM) (11\%). Among ACAS patients, after adjustment, IDDM was associated with a higher 30-day stroke/death (primary end point) compared with non-DM patients [odds ratio (OR) 2.3, 95\% CI: 1.5-3.4; $\mathrm{P}<0.001]$. In contrast, those with NIDDM experienced rates similar to those of non-DM patients $(2.1 \%$ vs. $1.5 \%$; $\mathrm{P}=0.1$ ) (31). Among symptomatic patients, after adjustment, those with IDDM and NIDDM experienced similar rates of the primary end point as those without DM. The high primary end point rates in ACAS patients with IDDM may limit any benefit from CEA (30).
MetS may precede T2DM $(31,32)$. Therefore, it is relevant to consider the relationship of MetS with carotid artery disease. Among a consecutive cohort of 752 patients undergoing CEA ( $n=314)$ and CAS $(n=438), 296(39.4 \%)$ participants had MetS (33). The authors selected a definition of MetS that included body mass index (BMI) (33) because they could not access to waist circumference measurements used by more widely recognized definitions of MetS (32). Patients with MetS had a significant increased risk in 30-day mortality, major adverse events (MAE) and restenosis rates after CEA or CAS (MAE: $5.3 \%$ vs. $2.7 \%$; death: $0.7 \%$ vs. $0.0 \%$; restenosis: $1.7 \%$ vs. $0.2 \% ; \mathrm{P}<0.05$ ). MAE and restenosis rates were still significantly different at 36 months, for both CEA and CAS. Among the diagnostic characteristics of MetS, fasting serum glucose, high-density lipoprotein cholesterol (HDL-C) and BMI were associated with increased complications both at 30 days and within 36 months (33).

A prospective study included 606 non-diabetic and 296 diabetic (83 were insulin-dependent) patients (3). The 30-day cumulative TIA/stroke rate was significantly higher in the diabetic group (2.6\% vs. $5.7 \%, \mathrm{P}=0.02)(3)$. Mortality was also significantly higher in this group (0.2 vs. $1.7 \%$, $\mathrm{P}=0.01)$. In multivariate analysis, among several factors, the use of insulin (OR 2.47, 95\% CI: 1.61-4.68; $\mathrm{P}=0.01$ ) and higher $\mathrm{HbA}_{1 \mathrm{c}}$ levels in those with $\mathrm{DM}(\mathrm{OR}=1.28,95 \%$ CI: $1.05-1.66, \mathrm{P}=0.03)$ increased the risk of all-cause death and stroke (3).

Patients $(n=17,800)$ from the Premier Healthcare Database who underwent CAS were retrospectively analysed. The group on statins $(n=12,416 ; 70 \%)$ had more symptomatic patients $(41 \%$ vs. $31 \% ; \mathrm{P}<0.001)$ and significantly more comorbidities, including hypertension, DM, coronary artery disease (CAD), dyslipidaemia, history of congestive heart failure, history of stroke, history of MI and PAD (all $\mathrm{P}<0.05$ ) (34). Despite this disadvantage, after adjustment for confounders, statin use was associated with a $64 \%$ reduction in death (OR $0.36,95 \%$ CI: $0.27-0.47$; $\mathrm{P}<0.001)$ and $18 \%$ reduction in stroke/death $(\mathrm{OR} 0.82$, 95\% CI: 0.68-0.99; P=0.03) (34).

A Korean study divided CEA patients into those with T2DM (n=265) and those without DM (n=410) (35). MAEs were defined as fatal or non-fatal stroke or MI or all-cause mortality. MAEs were assessed perioperatively and within 4 years after CEA. Multivariate analysis showed that DM was not associated with MAEs during the perioperative period (35). In contrast, within 4 years after CEA, DM was an independent risk factor for MAEs overall (HR 1.62, 
95\% CI: $1.06-2.48 ; \mathrm{P}=0.026)$ and stroke (HR 2.55, 95\% CI: $1.20-5.41 ; \mathrm{P}=0.015)$ (35).

In a retrospective review of CEA, CAS, endovascular and open aortic aneurysm repair as well as other procedures (36), 366 patients $(34.8 \%)$ had perioperative hyperglycaemia defined as $\geq 1$ glucose value $>180 \mathrm{mg} / \mathrm{dL}(10.0 \mathrm{mmol} / \mathrm{L})$ within $72 \mathrm{~h}$ of surgery. This was associated with a greater 30 -day mortality $(5.7 \%$ vs. $0.7 \% ; \mathrm{P}<0.01)$ and an increased risk of acute kidney failure $(4.9 \%$ vs. $0.9 \% ; \mathrm{P}<0.01)$, postoperative stroke $(3.0 \%$ vs. $0.7 \% ; \mathrm{P}<0.01)$ and surgical site infections (5.7\% vs. $2.6 \% ; \mathrm{P}=0.01)$. These patients were more likely to require reoperation $(6.3 \%$ vs. $1.8 \% ; \mathrm{P}<0.01)$ or readmission (12.3\% vs. $7.9 \% ; \mathrm{P}=0.02)$ (36). Multivariable logistic regression demonstrated that perioperative hyperglycaemia was related to a higher 30-day mortality and negative postoperative outcomes, including MI, stroke, kidney failure and wound complications (36).

In a survey (37) of adults hospitalised between 2007 and 2011 in the U.S., 128,664 patients (aged $\geq 45$ years) underwent CEA or CAS; of those, 41,120 had DM. Uncomplicated DM was not associated with higher odds of perioperative outcomes. In contrast, DM with chronic complications was a significant risk factor in those undergoing CEA (perioperative infection (OR 2.45, 95\% CI: 1.29-4.65), longer hospital stay [ $\beta$ (regression coefficient indicating number of days): $2.05,95 \%$ CI: $1.90-2.20]$ and mortality (OR 1.48, 95\% CI: 1.01-2.16) compared with patients without DM. Those with DM and chronic complications undergoing CAS had significantly increased odds of acute kidney injury (OR 3.17, 95\% CI: 2.31-4.35) and longer hospital stay ( $\beta$ : $1.98,95 \%$ CI: $1.58-2.38$ ) compared with patients without DM (37).

In contrast with the results described above, another study (38) showed that T2DM even without clinical evident CVD was associated with a greater risk of MACE (fatal or non-fatal stroke, MI and all-cause mortality). In patients with T2DM ( $\mathrm{n}=2,006$; aged $>50$ years) without clinical evident CVD, the risk of MACE was significantly $(\mathrm{P}<0.001)$ greater in those with both longer duration of $\mathrm{DM}$ $(\geq 10$ years) and significant carotid artery stenosis (50-69\% stenosis), compared with those with shorter duration and/or non-significant carotid artery stenosis (38).

The increased risk of perioperative events in patients with DM was supported by the findings of a meta-analysis published in 2016 (39). This meta-analysis included ten CEA, three CAS studies and one study where both CEA and CAS were carried out [total $=16,264$ patients; $26 \%$ $(\mathrm{n}=4,204)$ had DM] (39).
One reason for the greater risk of carotid-related complications in patients with DM may be that they have more carotid plaques with calcification and lipidrich necrotic core compared with non-diabetic patients [as visualized by magnetic resonance imaging (MRI)] (40). However, this potential interpretation requires confirmation.

\section{Comments}

There is convincing evidence that DM confers a greater risk of adverse outcomes after CEA or CAS, especially if DM is associated with complications. This is clearly illustrated by the inclusion of DM in the NSQIP (National Surgical Quality Improvement Program) registry that predicts adverse outcomes (30-day adverse events: stroke, $\mathrm{MI}$ or death) after CEA for ACAS or symptomatic carotid stenosis (41). The OR in the prediction model for non-insulin dependent DM was 1.41 (95\% CI: 1.10-1.81; $\mathrm{P}=0.007$ ) and for insulin dependent $\mathrm{DM}$, the corresponding values were 1.55 (95\% CI: $1.15-2.08 ; \mathrm{P}=0.004)$ (41).

There is a need to establish whether modifying risk factors (e.g., glycaemia and dyslipidaemia) in patients with DM can improve outcomes related to CRevasc. In this context, some of the evidence discussed above seems encouraging. It is also important to establish if "statin loading" pre-CEA and/or pre-CAS (or current longer-term statin use) confers any benefits in patients (including those with DM) $(1,2,42-46)$. Undoubtedly, vascular surgeons involved in carrying out CEA or CAS procedures need to be aware of the specific risks associated with DM.

\section{Carotid disease is associated with obesity and excess fat deposition in other organs}

\section{Epicardial fat thickness (EFT)}

EFT (assessed by transthoracic echocardiography) and cIMT (assessed by ultrasonography) were recorded in 76 T2DM patients without clinical atherosclerotic CVD and 30 age- and sex-matched controls (47). Patients with DM had significantly higher EFT and cIMT than controls $(6.23 \pm 1.27$ vs. $4.6 \pm 1.03 \mathrm{~mm}, \mathrm{P}<0.001$ and $0.77 \pm 0.15$ vs. $0.58 \pm 0.08 \mathrm{~mm}, \mathrm{P}<0.001$, respectively). Stepwise regression analysis showed that cIMT, duration of T2DM, triglyceride levels and BMI were the independent predictors of EFT, with cIMT as the most important predictor $(\mathrm{P}<0.001)$. These findings are of interest since EFT is a predictor of cardio-metabolic disease (47). 
Similar results for EFT, cIMT and presence of carotid plaque were reported by others (48). Furthermore, compared with a T2DM normoalbuminuric group, EFT and cIMT were significantly higher in those with T2DM and microalbuminuria $(\mathrm{P}<0.05$ for all $)$ (49). In logistic regression analysis, cIMT (OR 3.15, 95\% CI: 1.5-36.3, $\mathrm{P}=0.024)$ was independently related to the presence of microalbuminuria in these patients (49).

\section{Fatty liver}

Liver steatosis (as assessed by fatty liver index) was associated with carotid and coronary (but not femoral atherosclerosis) and with $\mathrm{CV}$ mortality risk (as assessed by the 10-year Framingham Risk Score) (50). In another study, after adjusting for several variables, logistic regression demonstrated that $\mathrm{HbA}_{1 \mathrm{c}}$ levels and fatty liver were independent predictors of cIMT (OR 1.426, 95\% CI: 1.084-1.876, $\mathrm{P}=0.011$ and $4.718,95 \%$ CI: $1.083-20.542$, $\mathrm{P}=0.039$, respectively) (51). This study was conducted in lean (BMI $23.3 \pm 4.6$ and $22.4 \pm 4.4 \mathrm{~kg} / \mathrm{m}^{2}$ ) adolescents with T1DM and with or without increased cIMT $(n=110$; mean age: $14.2 \pm 0.7$ years; mean duration of T1DM: $6.0 \pm 0.3$ years) (51). Mean visceral fat and liver size measured ultrasonographically were significantly higher in adolescents with increased cIMT (51).

\section{Perivascular fat}

A multivariable regression model showed that age $(\mathrm{P}<0.0001)$, perivascular adipose tissue $(\mathrm{PVAT})(\mathrm{P}<0.0001)$ and smoking $(\mathrm{P}=0.04)$ were independently associated with the severity of ICA stenosis (52). PVAT [expressed as extramedia thickness (EMT) to BMI ratio, EMT/BMI] was significantly increased in those with $\geq 50 \%$ carotid stenosis compared with those with $<50 \%$ carotid stenosis whether they had DM $(28.5 \pm 5$ vs. $24.7 \pm 4, \mathrm{P}<0.0001)$ or not $(28.8 \pm 6$ vs. $26.1 \pm 3.8, \mathrm{P}<0.001)(52)$.

In another study, the density of carotid perivascular fat was measured by computed tomography angiography (CTA) in 94 patients (52 asymptomatic and 42 symptomatic for stroke and TIA) with unilateral ICA stenosis $\geq 50-99 \%$ (53). Symptomatic patients (16.7\% had DM) had higher mean pericarotid fat density $(-66.2 \pm 19.2 v s .-77.1 \pm 20.4, \mathrm{P}=0.009)$ compared with asymptomatic patients $(32.7 \%$ had DM). In contrast, for non-stenotic ICAs, there was no significant difference between pericarotid fat density in symptomatic compared with asymptomatic patients (53). These findings suggest that inflammation associated with symptomatic carotid plaques extends beyond the vessel lumen and can be identified using CTA imaging (53).

Neck circumference was also significantly and independently associated with common carotid IMT, thus suggesting a possible effect of PVAT on atherosclerosis (54). Perhaps neck circumference should be measured more often and considered as an index of local excess fat?

Perivascular inflammation and local adiponectin levels may influence carotid intraplaque inflammatory activities $(55,56)$. These studies included patients with DM.

\section{Obesity, visceral adiposity and MetS}

Obesity and MetS are linked with vascular event risk as well as an increased probability of developing T2DM $(31,32)$. Therefore, some recent studies are worth a mention.

A Japanese community-based study ( $\mathrm{n}=1,241$ participants) compared metabolically healthy obese (MHO), metabolically unhealthy obese (MUO) and non-obese (BMI $<25.0 \mathrm{~kg} / \mathrm{m}^{2}$ ) participants in terms of the presence of carotid plaque (57). Multivariable analysis showed that MHO (OR 1.564, 95\% CI: $1.102-2.222, \mathrm{P}=0.012$ ) and MUO (OR 1.857, 95\% CI: $1.226-2.811, \mathrm{P}=0.003)$, as well as age $\geq 65$ years, male sex, hypertension and DM were independently associated with carotid plaque formation (57).

Another Japanese study $(\mathrm{n}=7,750)$ involving middle-aged participants without CVD undergoing health check-ups also found that obesity-related indices (i.e., BMI, \% body fat, visceral fat area and waist circumference) were positively associated with cIMT (58). Visceral fat area was assessed by CT (58).

Another study involved subjects (731 adults; median age: 47 years) free of CVD but who were at risk of developing DM (59). Visceral adiposity index (estimated based on waist circumference, BMI, triglyceride and HLD-C values) $(\mathrm{P}=0.0392)$ but not the homeostatic model assessment of insulin resistance $(\mathrm{P}=0.37)$ was associated with cIMT, independently of established CV risk factors (59).

\section{Comments}

Some years ago, we coined the term APIFat since several authors used the term "ectopic" fat to describe excess fat accumulation in several organs (60). Actually, fat is present within and "around" many organs under healthy conditions; the problem is excessive pathological fat deposition (e.g., in the obese and those with DM). This excessive fat accumulation is often associated with abnormal function 
which can be harmful. It follows that any excessive fat deposition is not "ectopic" since it is present in a usual location rather than in one where there is usually no fat at all. The word "ectopic" signals a factor that occurs outside its usual location (60).

The APIFat phenomenon includes several organs and, based on the above literature, the carotid arteries are not spared (60-62). This relationship may be relevant since there is evidence that APIFat is associated with adverse outcomes in various organs and also with vascular risk (60-62). For example, non-alcoholic fatty liver disease (NAFLD) and excess EFT are associated with an increased risk of vascular events and other conditions such as DM, MetS and obesity (60-63). Based on the literature above, the increased risk of vascular events in patients with carotid pathology may include a complex interaction of several factors. In this context, it is relevant that even ACAS is associated with an increased risk of vascular events (64).

All these associations are in need of further research to confirm their clinical relevance and consider potential diagnostic and treatment options. Among new potential measurements that may reflect perivascular fat, EMT may deserve further exploration (65).

\section{Other links with carotid disease}

$\mathrm{CV}$ autonomic neuropathy in normoalbuminuric patients with long-term T1DM is associated with increased generalised arterial calcification (including the carotid arteries) (66). It has also been proposed that hypertension, smoking and DM, can destabilize atheromatic plaques and enhance their calcification (67).

cIMT is negatively correlated with endothelial-dependent flow-mediated vasodilation, as well as with the circulating levels of endothelin-1 (a vasoconstrictor and activator of platelet function) and vascular endothelial growth factor $(68,69)$. These variables can be abnormal in patients with DM.

Associations between lipid variables and carotid disease will be the subject of another review within this series of articles (70). However, it is worth mentioning that elevated levels of lipoprotein (a) $[\mathrm{Lp}(\mathrm{a})]$ may increase the risk of carotid plaque presence $(71,72)$. This finding is interesting since the circulating levels of this lipoprotein are mainly genetically determined and new treatment options that can considerably lower $\mathrm{Lp}$ (a) levels are being developed $(72,73)$. Furthermore, we need to consider that the new proprotein convertase subtilisin/kexin 9 (PCSK9) inhibitors also lower $\mathrm{Lp}(\mathrm{a})$ as well as LDL-C levels $(72,73)$. Interestingly, there is evidence of an inverse relationship between $\mathrm{Lp}$ (a) levels and risk of T2DM [greater risk of T2DM at low Lp(a) levels] (74).

Increased cIMT was also associated with ocular ischaemia and mild non-proliferative diabetic retinopathy (NPDR) in patients with T2DM. This finding, if confirmed, supports the hypothesis that cIMT may be an early predictor of mild NPDR (75).

\section{Carotid bruits}

The role of carotid bruits is worth a mention. There is evidence from a meta-analysis and a review that the presence of carotid bruits predicts CV risk $(76,77)$. For example, in a meta-analysis of 4 trials comparing patients with and without carotid bruits, the OR for MI was 2.15 (95\% CI: 1.67-2.78) and for CV death 2.27 (95\% CI: 1.49-3.49) (76). However, such conclusions are not without some limitations (78).

More specifically related to DM, in 2003, the Fremantle Diabetes Study (79) reported, based on a communitybased sample, reported that in the first 2 years, first stroke $(\mathrm{n}=45 / 1,181 ; 3.8 \%)$ was strongly predicted by the presence of carotid bruits after adjusting for $\mathrm{CV}$ risk factors and potential confounders (HR 6.7; 95\% CI: 3.0-14.9; $\mathrm{P}<0.001$ ). This relationship was not sustained on a more prolonged follow-up (79). As expected, age and diastolic blood pressure were also determinants of stroke in the first 2 years (79). Age, atrial fibrillation/flutter, and microalbuminuria were additional independent predictors of stroke at 2 years (79).

Carotid bruits may be absent in patients with ICA occlusion. Yet these patients are likely to have many vascular risk factors (including DM) and atherosclerotic disease at other sites (80).

\section{Contrast-induced acute kidney injury (CI-AKI)}

CAS could be associated with CI-AKI (81). This factor did not seem to be recorded when CEA vs. CAS were compared in terms of outcomes (81). CI-AKI is relevant because it can influence both short- and long-term outcomes (82-84). Moreover, DM is a risk factor for CI-AKI (85). In addition, the use of metformin should be considered in patients with DM receiving a contrast medium (86).

\section{Concluding comments}

Based on the above evidence, there is more to carotid disease than just "local" arterial pathology, especially if DM is also present. It is therefore not surprising that there has 
been a huge increase in the "carotid diabetes" literature (see Table 1).

Moreover, there is a need for the better understanding of the role of perivascular fat in patient outcomes. In this context, it is of interest that evidence shows that perivascular fat surrounding various arteries has different properties (87-89). Therefore, it is possible that carotid perivascular fat has to be specifically studied. To this "regional specificity" of perivascular fat, we need to add the possibility that different arteries may show variation in their receptor populations (90) and DM may affect that pattern. In addition, vascular risk factors may not affect all arteries equally (91). We still have a lot to learn!

Physicians and vascular surgeons involved in looking after patients with carotid disease and DM have to consider several factors that will influence patient outcomes. There is also an urgent need for further research to optimise the assessment and treatment of these patients.

\section{Acknowledgments}

Funding: None.

\section{Footnote}

Provenance and Peer Review: This article was commissioned by the Guest Editor (Dr. Kosmas I. Paraskevas) for the series "Carotid Artery Stenosis and Stroke: Prevention and Treatment Part I" published in Annals of Translational Medicine. The article has undergone external peer review.

Conflicts of Interest: Both authors have completed the ICMJE uniform disclosure form (available at http://dx.doi. org/10.21037/atm.2019.12.153). N Katsiki has given talks, attended conferences and participated in trials sponsored by Astra Zeneca, Bausch Health, Boehringer Ingelheim, Elpen, MSD, Mylan, Novo Nordisk, Sanofi and Servier. DP Mikhailidis has given talks, acted as a consultant or attended conferences sponsored by Amgen, Novo Nordisk and Libytec.

Ethical Statement: The authors are accountable for all aspects of the work in ensuring that questions related to the accuracy or integrity of any part of the work are appropriately investigated and resolved.

Open Access Statement: This is an Open Access article distributed in accordance with the Creative Commons
Attribution-NonCommercial-NoDerivs 4.0 International License (CC BY-NC-ND 4.0), which permits the noncommercial replication and distribution of the article with the strict proviso that no changes or edits are made and the original work is properly cited (including links to both the formal publication through the relevant DOI and the license). See: https://creativecommons.org/licenses/by-nc-nd/4.0/.

\section{References}

1. Cosentino F, Grant PJ, Aboyans V, et al. 2019 ESC Guidelines on diabetes, pre-diabetes, and cardiovascular diseases developed in collaboration with the EASD. Eur Heart J 2020;41:255-323.

2. Naylor AR, Ricco JB, de Borst GJ, et al. Editor's Choice - Management of Atherosclerotic Carotid and Vertebral Artery Disease: 2017 Clinical Practice Guidelines of the European Society for Vascular Surgery (ESVS). Eur J Vasc Endovasc Surg 2018;55:3-81.

3. Dimic A, Markovic M, Vasic D, et al. Impact of diabetes mellitus on early outcome of carotid endarterectomy. Vasa 2019;48:148-56.

4. Wei LM, Zhu YQ, Bao YQ, et al. Atherosclerosis in intracranial or extracranial vessels in diabetic patients and the association with stroke subtype. Quant Imaging Med Surg 2019;9:960-7.

5. Liapis CD, Bell PF, Mikhailidis DP, et al.; ESVS Guidelines Collaborators; European Society for Vascular Surgery. ESVS Guidelines: Section A--prevention in patients with carotid stenosis. Curr Vasc Pharmacol 2010;8:673-81.

6. Lu J, Ma X, Shen Y, et al. Time in Range Is Associated with Carotid Intima-Media Thickness in Type 2 Diabetes. Diabetes Technol Ther 2019. [Epub ahead of print].

7. Hoke M, Schillinger M, Minar E, et al. Carotid ultrasound investigation as a prognostic tool for patients with diabetes mellitus. Cardiovasc Diabetol 2019;18:90.

8. Zhang Y, Zhang H, Li P. Cardiovascular risk factors in children with type 1 diabetes mellitus. J Pediatr Endocrinol Metab 2019;32:699-705.

9. Giannopoulou EZ, Doundoulakis I, Antza C, et al. Subclinical arterial damage in children and adolescents with type 1 diabetes: A systematic review and metaanalysis. Pediatr Diabetes 2019;20:668-77.

10. Sundholm JKM, Litwin L, Rönö K, et al. Maternal obesity and gestational diabetes: Impact on arterial wall layer thickness and stiffness in early childhood - RADIEL study six-year follow-up. Atherosclerosis 2019;284:237-44. 
11. Cardoso CRL, Leite NC, Bacan G, et al. Prognostic Importance of Resistant Hypertension in Patients With Type 2 Diabetes: The Rio de Janeiro Type 2 Diabetes Cohort Study. Diabetes Care 2020;43:219-27.

12. Cardoso CRL, Salles GC, Leite NC, et al. Prognostic impact of carotid intima-media thickness and carotid plaques on the development of micro- and macrovascular complications in individuals with type 2 diabetes: the Rio de Janeiro type 2 diabetes cohort study. Cardiovasc Diabetol 2019;18:2.

13. Zhao Y, Evans MA, Allison MA, et al. Multisite atherosclerosis in subjects with metabolic syndrome and diabetes and relation to cardiovascular events: The Multi-Ethnic Study of Atherosclerosis. Atherosclerosis 2019;282:202-9.

14. Zhang M, Wen X, Zhou C, et al. Carotid intima-media thickness and plaques in internal carotid artery as surrogate markers of lower limb arterial lesions in Chinese patients with diabetic foot. Braz J Med Biol Res 2019;52:e8432.

15. Katakami N, Matsuoka TA, Shimomura I. Clinical utility of carotid ultrasonography: Application for the management of patients with diabetes. J Diabetes Investig 2019;10:883-98.

16. Paraskevas KI, Sillesen HH, Rundek T, et al. Carotid Intima-Media Thickness Versus Carotid Plaque Burden for Predicting Cardiovascular Risk. Angiology 2020;71:108-11.

17. Shore AC, Colhoun HM, Natali A, et al; SUMMIT Consortium. Use of Vascular Assessments and Novel Biomarkers to Predict Cardiovascular Events in Type 2 Diabetes: The SUMMIT VIP Study. Diabetes Care 2018;41:2212-9.

18. Palanca A, Castelblanco E, Betriu À, et al. Subclinical atherosclerosis burden predicts cardiovascular events in individuals with diabetes and chronic kidney disease. Cardiovasc Diabetol 2019;18:93.

19. Che Q, Yang Y, Cheng G, et al. Decreased GFR and its joint association with type 2 diabetes and hypertension with prevalence and severity of carotid plaque in a community population in China. Diabetes Metab Syndr Obes 2019;12:1263-73.

20. Nattero-Chávez L, Redondo López S, Alonso Díaz S, et al. The peripheral atherosclerotic profile in patients with type 1 diabetes warrants a thorough vascular assessment of asymptomatic patients. Diabetes Metab Res Rev 2019;35:e3088.

21. Pan Z, Wang R, Li L, et al. Correlation between significant asymptomatic carotid artery stenosis and severity of peripheral arterial occlusive disease in the lower limb: a retrospective study on 200 patients. BMC Neurol 2019;19:259.

22. Pan FS, Xu M, Yu L, et al. Relationship between carotid intima-media thickness and carotid artery stiffness assessed by ultrafast ultrasound imaging in patients with type 2 diabetes. Eur J Radiol 2019;111:34-40.

23. Kozakova M, Morizzo C, Goncalves I, et al. Cardiovascular organ damage in type 2 diabetes mellitus: the role of lipids and inflammation. Cardiovasc Diabetol 2019;18:61.

24. Sharif S, Visseren FLJ, Spiering W, et al.; SMART study group. Arterial stiffness as a risk factor for cardiovascular events and all-cause mortality in people with Type 2 diabetes. Diabet Med 2019;36:1125-32.

25. Castelblanco E, Betriu À, Hernández M, et al. Ultrasound Tissue Characterization of Carotid Plaques Differs Between Patients with Type 1 Diabetes and Subjects without Diabetes. J Clin Med 2019. doi: 10.3390/ jcm8040424.

26. Katsiki N, Banach M, Mikhailidis DP. Is type 2 diabetes mellitus a coronary heart disease equivalent or not? Do not just enjoy the debate and forget the patient! Arch Med Sci 2019;15:1357-64.

27. Macharzina RR, Müller C, Vogt M, et al. The SAPPHIRE criteria, history of myocardial infarction and diabetes predict adverse outcomes following carotid endarterectomy similar to stenting. Clin Res Cardiol 2020;109:589-98.

28. Lim S, Mora-Pinzon M, Park T, et al. Medical therapy does not confer stroke prevention for all patients: identification of high-risk patients with asymptomatic carotid stenosis is still needed. Int Angiol 2019;38:372-80.

29. Texakalidis P, Tzoumas A, Giannopoulos S, et al. Risk Factors for Restenosis After Carotid Revascularization: A Meta-Analysis of Hazard Ratios. World Neurosurg 2019;125:414-24.

30. Pothof AB, O'Donnell TFX, Swerdlow NJ, et al. Risk of insulin-dependent diabetes mellitus in patients undergoing carotid endarterectomy. J Vasc Surg 2019;69:814-23.

31. Isomaa B, Almgren P, Tuomi T, et al. Cardiovascular morbidity and mortality associated with the metabolic syndrome. Diabetes Care 2001;24:683-9.

32. Alberti KG, Eckel RH, Grundy SM, et al.; International Diabetes Federation Task Force on Epidemiology and Prevention; Hational Heart, Lung, and Blood Institute; American Heart Association; World Heart Federation; International Atherosclerosis Society; International Association for the Study of Obesity. Harmonizing the Metabolic Syndrome. A Joint Interim Statement of 
the International Diabetes Federation Task Force on Epidemiology and Prevention; National Heart, Lung, and Blood Institute; American Heart Association; World Heart Federation; International Atherosclerosis Society; and International Association for the Study of Obesity. Circulation 2009;120:1640-5.

33. Casana R, Malloggi C, Tolva VS, et al. Does metabolic syndrome influence short and long term durability of carotid endarterectomy and stenting? Diabetes Metab Res Rev 2019;35:e3084.

34. Rizwan M, Faateh M, Dakour-Aridi H, et al. Statins reduce mortality and failure to rescue after carotid artery stenting. J Vasc Surg 2019;69:112-9.

35. Jeong MJ, Kwon H, Jung CH, et al. Comparison of outcomes after carotid endarterectomy between type 2 diabetic and non-diabetic patients with significant carotid stenosis. Cardiovasc Diabetol 2019;18:41.

36. Long CA, Fang ZB, Hu FY, et al. Poor glycemic control is a strong predictor of postoperative morbidity and mortality in patients undergoing vascular surgery. J Vasc Surg 2019;69:1219-26.

37. Adegbala O, Martin KD, Otuada D, et al. Diabetes Mellitus with Chronic Complications in Relation to Carotid Endarterectomy and Carotid Artery Stenting Outcomes. J Stroke Cerebrovasc Dis 2017;26:217-24.

38. Noh M, Kwon H, Jung CH, et al. Impact of diabetes duration and degree of carotid artery stenosis on major adverse cardiovascular events: a single-center, retrospective, observational cohort study. Cardiovasc Diabetol 2017;16:74.

39. Hussain MA, Bin-Ayeed SA, Saeed OQ, et al. Impact of diabetes on carotid artery revascularization. J Vasc Surg 2016;63:1099-107.e4.

40. Gao X, Song J, Watase H, et al.; CARE-II Investigators. Differences in Carotid Plaques Between Symptomatic Patients With and Without Diabetes Mellitus. Arterioscler Thromb Vasc Biol 2019;39:1234-9.

41. Dasenbrock HH, Smith TR, Gormley WB, et al. Predictive Score of Adverse Events After Carotid Endarterectomy: The NSQIP Registry Carotid Endarterectomy Scale. J Am Heart Assoc 2019;8:e013412.

42. Paraskevas KI, Liapis CD, Hamilton G, et al. Can statins reduce perioperative morbidity and mortality in patients undergoing non-cardiac vascular surgery? Eur J Vasc Endovasc Surg 2006;32:286-93.

43. Paraskevas KI, Veith FJ, Liapis CD, et al. Perioperative/ periprocedural effects of statin treatment for patients undergoing vascular surgery or endovascular procedures: an update. Curr Vasc Pharmacol 2013;11:112-20.

44. Reiff T, Amiri H, Rohde S, et al. Statins reduce periprocedural complications in carotid stenting. Eur J Vasc Endovasc Surg 2014;48:626-32.

45. Avgerinos ED, Kakisis JD, Moulakakis KG, et al. Statins influence long term restenosis and cardiovascular events following carotid endarterectomy. Curr Vasc Pharmacol 2015;13:239-47.

46. Katsiki N, Triposkiadis F, Giannoukas AD, et al. Statin loading in cardiovascular surgery: never too early to treat. Curr Opin Cardiol 2018;33:436-43.

47. Yafei S, Elsewy F, Youssef E, et al. Echocardiographic association of epicardial fat with carotid intima-media thickness in patients with type 2 diabetes. Diab Vasc Dis Res 2019;16:378-84.

48. Erdoğan T, Durakoğlugil ME, Çetin M, et al. Epicardial Adipose Tissue Predicts Carotid Intima-Media Thickness Independently of Body Mass Index and Waist Circumference. Acta Cardiol Sin 2019;35:32-41.

49. Turan Y, Turan E. Aortic Stiffness Index And Carotid Intima-Media Thickness Are Independently Associated With The Presence Of Microalbuminuria In Patients With Type 2 Diabetes Mellitus. Diabetes Metab Syndr Obes 2019;12:1889-96.

50. Pais R, Redheuil A, Cluzel P, et al. Relationship Among Fatty Liver, Specific and Multiple-Site Atherosclerosis, and 10-Year Framingham Score. Hepatology 2019;69:1453-63.

51. Atwa H, Gad K, Hagrasy H, et al. Is subclinical atherosclerosis associated with visceral fat and fatty liver in adolescents with type 1 diabetes? Arch Med Sci 2018;14:1355-60.

52. Haberka M, Skilton M, Biedroń M, et al. Obesity, visceral adiposity and carotid atherosclerosis. J Diabetes Complications 2019;33:302-6.

53. Baradaran H, Myneni PK, Patel P, et al. Association Between Carotid Artery Perivascular Fat Density and Cerebrovascular Ischemic Events. J Am Heart Assoc 2018;7:e010383.

54. Baena CP, Lotufo PA, Santos IS, et al. Neck circumference is associated with carotid intimal-media thickness but not with coronary artery calcium: Results from The ELSABrasil. Nutr Metab Cardiovasc Dis 2016;26:216-22.

55. Luo X, Li W, Bai Y, et al. Relation between carotid vulnerable plaques and peripheral leukocyte: a case-control study of comparison utilizing multi-parametric contrastenhanced ultrasound. BMC Med Imaging 2019;19:74.

56. Sharma G, Tao M, Ding K, et al. Perivascular adipose adiponectin correlates with symptom status of 
patients undergoing carotid endarterectomy. Stroke 2015;46:1696-9.

57. Itoh H, Kaneko H, Kiriyama H, et al. Effect of Metabolically Healthy Obesity on the Development of Carotid Plaque in the General Population: A Community-Based Cohort Study. J Atheroscler Thromb 2020;27:155-163.

58. Sugiura T, Dohi Y, Takagi Y, et al. Relationships of Obesity-Related Indices and Metabolic Syndrome with Subclinical Atherosclerosis in Middle-Aged Untreated Japanese Workers. J Atheroscler Thromb 2019. [Epub ahead of print].

59. Randrianarisoa E, Lehn-Stefan A, Hieronimus A, et al. Visceral Adiposity Index as an Independent Marker of Subclinical Atherosclerosis in Individuals Prone to Diabetes Mellitus. J Atheroscler Thromb 2019;26:821-34.

60. Katsiki N, Athyros VG, Mikhailidis DP. Abnormal PeriOrgan or Intra-organ Fat (APIFat) Deposition: An Underestimated Predictor of Vascular Risk? Curr Vasc Pharmacol 2016;14:432-41.

61. Katsiki N, Dimitriadis G, Mikhailidis DP. Perirenal Adiposity and Other Excessive Intra- and Peri-Organ Fat Depots: What Is the Connection? Angiology 2019;70:581-3.

62. Katsiki N, Mikhailidis DP. Abnormal Peri-Organ or Intra-Organ Fat Deposition and Vascular Risk. Angiology 2018;69:841-2.

63. Katsiki N, Mikhailidis DP. Epicardial fat: a novel marker of subclinical atherosclerosis in clinical practice? Anatol J Cardiol 2017;17:64-5.

64. Giannopoulos A, Kakkos S, Abbott A, et al. Long-term Mortality in Patients with Asymptomatic Carotid Stenosis: Implications for Statin Therapy. Eur J Vasc Endovasc Surg 2015;50:573-82.

65. Domienik-Karłowicz J, Lisik W, Kosieradzki M, et al. Emerging measurements of atherosclerosis: extra-media thickness, epicardial adipose tissue, and periarterial adipose tissue intima media adventitia index in morbidly obese patients undergoing bariatric surgery. Wideochir Inne Tech Maloinwazyjne 2019;14:249-54.

66. Hjortkjær HØ, Jensen T, Hilsted J, et al. Generalised arterial calcification in normoalbuminuric patients with type 1 diabetes with and without cardiovascular autonomic neuropathy. Diab Vasc Dis Res 2019;16:98-102.

67. .Scimeca M, Anemona L, Granaglia A, et al. Plaque calcification is driven by different mechanisms of mineralization associated with specific cardiovascular risk factors. Nutr Metab Cardiovasc Dis 2019;29:1330-6.
68. Jagroop IA, Daskalopoulou SS, Mikhailidis DP.

Endothelin-1 and human platelets. Curr Vasc Pharmacol 2005;3:393-9.

69. Wang M, Sui J, Wang S, et al. Correlations of carotid intima-media thickness with endothelial function and atherosclerosis degree in patients with type 2 diabetes mellitus. Clin Hemorheol Microcirc 2019;72:431-9.

70. Paraskevas KI, Veith FJ, Eckstein HH, et al. Cholesterol, carotid artery disease and stroke: what the vascular specialist needs to know. Ann Transl Med 2020;8:1265.

71. Steffen BT, Thanassoulis G, Duprez D, et al. RaceBased Differences in Lipoprotein(a)-Associated Risk of Carotid Atherosclerosis. Arterioscler Thromb Vasc Biol 2019;39:523-9.

72. Katsiki N, Al-Rasadi K, Mikhailidis DP. Lipoprotein (a) and Cardiovascular Risk: The Show Must go on. Curr Med Chem 2017;24:989-1006.

73. Kolovou GD, Katsiki N, Mikhailidis DP. Editorial: Lipoprotein (a), More than Just Cholesterol? Curr Med Chem 2017;24:952-6.

74. Paige E, Masconi KL, Tsimikas S, et al. Lipoprotein(a) and incident type-2 diabetes: results from the prospective Bruneck study and a meta-analysis of published literature. Cardiovasc Diabetol 2017;16:38.

75. Ichinohasama K, Kunikata H, Ito A, et al. The Relationship between Carotid Intima-Media Thickness and Ocular Circulation in Type-2 Diabetes. J Ophthalmol 2019;2019:3421305.

76. Pickett CA, Jackson JL, Hemann BA, et al. Carotid bruits as a prognostic indicator of cardiovascular death and myocardial infarction: a meta-analysis. Lancet 2008;371:1587-94.

77. Paraskevas KI, Hamilton G, Mikhailidis DP. Clinical significance of carotid bruits: an innocent finding or a useful warning sign? Neurol Res 2008;30:523-30.

78. Aboyans V, Lacroix P. Carotid bruit: good for silent cardiovascular disease? Lancet 2008;371:1554-6.

79. Gillett M, Davis WA, Jackson D, et al. Prospective evaluation of carotid bruit as a predictor of first stroke in type 2 diabetes: the Fremantle Diabetes Study. Stroke 2003;34:2145-51.

80. Paraskevas KI, Mikhailidis DP, Liapis CD. Internal carotid artery occlusion: association with atherosclerotic disease in other arterial beds and vascular risk factors. Angiology 2007;58:329-35.

81. Paraskevas KI, Mikhailidis DP. Contrast-Induced Acute Kidney Injury in Patients Undergoing Carotid Artery Stenting: An Underestimated Issue. Angiology 
2017;68:752-6.

82. Katsiki N, Athyros VG, Karagiannis A, et al. ContrastInduced Nephropathy: An "All or None" Phenomenon? Angiology 2015;66:508-13.

83. Uzunhasan I, Yildiz A, Arslan S, et al. Contrast-Induced Acute Kidney Injury Is Associated With Long-Term Adverse Events in Patients With Acute Coronary syndrome. Angiology 2017;68:621-6.

84. Sun G, Chen P, Wang K, et al. Contrast-Induced Nephropathy and Long-Term Mortality After Percutaneous Coronary Intervention in Patients With Acute Myocardial Infarction. Angiology 2019;70:621-6.

85. Katsiki N, Fonseca V, Mikhailidis DP. Contrast-induced acute kidney injury in diabetes mellitus: Clinical relevance and predisposing factors. Could statins be of benefit? J Diabetes Complications 2018;32:982-4.

86. van der Molen AJ, Reimer P, Dekkers IA, et al. Postcontrast acute kidney injury. Part 2: risk stratification, role of hydration and other prophylactic measures, patients taking metformin and chronic dialysis patients:
Recommendations for updated ESUR Contrast Medium Safety Committee guidelines. Eur Radiol 2018;28:2856-69.

87. Grigoras A, Amalinei C, Balan RA, et al. Perivascular adipose tissue in cardiovascular diseases-an update. Anatol J Cardiol 2019;22:219-31.

88. Randrianarisoa E, Stefan N, Fritsche A, et al. Periaortic adipose tissue compared with peribrachial adipose tissue mass as markers and possible modulators of cardiometabolic risk. Angiology 2018;69:854-60.

89. Katsiki N, Mikhailidis DP. Perivascular adipose tissue in cardiovascular diseases. Anatol J Cardiol 2020;23:58.

90. Alnaeb ME, Thompson CS, Seifalian AM, et al. Regional differences in the expression of nitric oxide synthase and specific receptors in the vascular tissues of control and diabetic rabbits: a pilot study. In Vivo 2007;21:1069-74.

91. Paraskevas KI, Bessias N, Papas TT, et al. Do different vascular risk factors affect all arteries equally? Angiology 2008;59:397-401.

Cite this article as: Katsiki N, Mikhailidis DP. Diabetes and carotid artery disease: a narrative review. Ann Transl Med 2020;8(19):1280. doi: 10.21037/atm.2019.12.153 